\title{
PRÁTICAS MULTILETRADAS NA FORMAÇÃO DE LEITORES NA INFÂNCIA
}

\section{MULTILITERACIES PRACTICES IN THE READERS' FORMATION IN THE CHILDHOOD}

\author{
Paulo Henrique Machado ${ }^{1}$ \\ Maria de Lourdes Rossi Remenche ${ }^{2}$
}

\begin{abstract}
RESUMO: O presente estudo tem como objetivo analisar as práticas multiletradas mobilizadas por Livros Literários Infantis digitais interativos em formato de Aplicativos (LLIA) que contribuem para a formação do leitor literário na infầncia. Para tanto, delimitou-se como corpus de análise a obra "Wuwu \& Co.: a magical picture book" (HELLE; SLOCINSKA, 2015), vencedora do BolognaRagazzi Digital Award (Feira do Livro Infantil de Bolonha, Itália) de 2016, na categoria ficção digital. Trata-se de pesquisa qualitativo-interpretativista (MINAYO, 2001; MOITA LOPES, 1996), cujo arcabouço teórico-metodológico ancora-se nos estudos dos multiletramentos (NEW LONDON GROUP, 2000; COPE; KALANTZIS, 2009a, 2009b, 2010; KLEIMAN; SITO, 2016), nas análises multimodais de livros digitais de literatura infantil (SERAFINI, 2010; YOKOTA; TEALE, 2014; FREDERICO, 2016; MENEGAZZI, 2018), entre outros. A análise evidenciou que na interação com a obra selecionada, o leitor/agenciador é interpelado a fazer ligações não-lineares entre objetos distintos, possibilitando a interferência na narrativa literária. Verificou-se que a presença de múltiplas combinações multimodais/multissemióticas nos LLIA, aliada à agentividade do leitor e às potencialidades das tecnologias digitais, demanda maior interatividade, além de acionar modos diferenciados de leitura que contribuem para a produção de sentido. A investigação demonstrou que a linguagem verbovisual em LLIA suscita adaptação, vislumbrando a exploração dos recursos digitais multi/hipermídia, assim como requer a mobilização de outros canais sensoriais por parte dos leitores, configurando-se, deste modo, como linguagem multissensorial.
\end{abstract}

PALAVRAS-CHAVE: Literatura infantil. Livros digitais interativos. Multiletramentos.

\begin{abstract}
This study aims to analyze the multiliteracies practices mobilized by picture book apps that contribute to the formation of the literary reader in childhood. Being that, the following book app were chosen as corpus: "Wuwu \& Co.: a magical picture book" (HELLE; SLOCINSKA, 2015), winner of the BolognaRagazzi Digital Award (Bologna Children's Book Fair, Italy) in the year 2016, in the digital fiction category. This is a qualitative-interpretative research (MINAYO, 2001; MOITA LOPES, 1996), whose theoretical-methodological framework is anchored in multiliteracies studies (NEW LONDON GROUP, 2000; COPE; KALANTZIS, 2009a, 2009b, 2010; KLEIMAN; SITO, 2016), in the multimodal analysis of digital books of children's literature (SERAFINI, 2010; YOKOTA; TEALE, 2014; FREDERICO, 2016; MENEGAZZI, 2018), among others. The analysis showed that in the interaction with this picture book app, the reader/agency is invited to make nonlinear links between different objects, allowing to interfere in the literary narrative. It has been confirmed that the presence of multiple multimodal combinations in children's literature book apps, coupled with reader agentivity and the affordances of digital technologies, requires more interactivity on the part of the reader and triggers differentiated modes of reading that contribute to the production of meaning. This research shown that the verbvisual language in picture book app is adaptive, foreseeing the exploration of multi/hypermedia digital resources, as well as requires the mobilization of other sensory channels by readers, thus configuring itself as a multisensory language.
\end{abstract}

KEYWORDS: Children's literature. Interactive digital books. Multiliteracies.

\section{Considerações iniciais}

As tecnologias digitais têm assumido uma função significativa na organização cultural da modernidade recente, determinando mudanças na dinâmica da vida dos sujeitos. Presenciase a criação de sistemas computacionais desenvolvidos para interagirem com pessoas,

\footnotetext{
${ }^{1}$ Mestre em Estudos de Linguagens pela Universidade Tecnológica Federal do Paraná (UTFPR). Gestor da Informação na Prefeitura Municipal de Curitiba. E-mail: phenrique14@yahoo.com.br

${ }^{2}$ Doutora em Linguística pela Faculdade de Filosofia, Letras e Ciências Humanas da Universidade de São Paulo (USP). Docente do Programa de Pós-Graduação em Estudos de Linguagens (PPGEL) da Universidade Tecnológica Federal do Paraná (UTFPR). E-mail: mremenche@utfpr.edu.br
} 
embutidos nos mais diferentes dispositivos eletrônicos, que combinam poder computacional e meios de comunicação e de expressão.

Consequentemente, a sociedade tem vivenciado novas formas de utilização da linguagem, em decorrência das alterações nas formas de ler e escrever nos diferentes espaçotempos propiciados pela cibercultura. Os textos contemporâneos apresentam elementos multimodais em constante renovação e recursos com maior grau de interação, diversificandose na forma e no conteúdo com elementos de natureza multissemiótica. Tais semioses acionam práticas multiletradas como, por exemplo, a apropriação de recursos tecnológicos para a realização da leitura.

Nesse panorama, ser leitor na contemporaneidade pressupõe interação para além do impresso, ao passo que as transformações dos modos e suportes de leitura interferem nos moldes dos novos leitores. As mudanças no funcionamento, na forma e na função dos artefatos de leitura afetam não só aos leitores diretos, como toda sociedade. Verifica-se que o livro de literatura infantil impresso, que por tempos se manteve como o principal suporte de textos verbais, visuais e verbovisuais, enfrenta a concorrência de formatos digitais que incorporam múltiplas semioses (incluindo as dimensões auditivas, táteis e performativas) e possibilitam novas formas de interação textos-sujeitos, impactando, sobretudo, nos processos de leitura e de letramento literário. Esses livros digitais surgem principalmente como aplicativos (software) para dispositivos móveis de interação (e-readers, smartphones, tablets, entre outros) com telas sensíveis ao toque (tecnologia touchscreen) - daí deriva o nome livro aplicativo ou book app, em inglês.

Constata-se que as crianças, ao passo em que são mediadas pelos seus formadores, interagem com os textos digitais e com a própria materialidade textual, em seus diferentes suportes. Cada vez mais cedo, elas utilizam dispositivos eletrônicos portáteis repletos de recursos interativos, impulsionando o crescimento do mercado de aplicativos infantis de todos os tipos: educativos, jogos, leitura informacional e, por sua vez, leitura literária.

Como as práticas de leitura vêm passando por um processo de mudança que possibilita experimentações literárias e agenciamento, em virtude das diferentes configurações eletrônicas, a presente pesquisa tem como objetivo analisar as práticas multiletradas mobilizadas pelos Livros Literários Infantis digitais interativos em formato de Aplicativos (LLIA) que contribuem para a formação do leitor literário na infância. Têm-se como corpus de análise a obra "Wuwu \& Co.: a magical picture book", vencedora do BolognaRagazzi Digital Award (Feira do Livro Infantil de Bolonha, Itália) ${ }^{3}$ de 2016, na categoria ficção digital.

Trata-se de pesquisa qualitativo-interpretativista, cujo arcabouço teórico-metodológico se apoia nos estudos da literatura infantil digital, dos livros digitais interativos, do letramento literário, dos multiletramentos, entre outros.

Apresenta-se na sequência um breve percurso das perspectivas teórico-conceituais. Posteriormente, o percurso metodológico da pesquisa para, em seguida, a apresentação e discussão dos resultados. As considerações finais compõem a seção 5, que faz uma síntese da investigação descrita neste estudo.

\footnotetext{
${ }^{3}$ A Feira do Livro Infantil de Bolonha (Bologna Children's Book Fair, em inglês; Bologna Fiere, em italiano), é o maior e mais importante evento de literatura infantil e juvenil mundial. Acontece anualmente, desde 1964, na cidade italiana de mesmo nome, e reúne autores, ilustradores, editores, bibliotecários, designers gráficos e outros profissionais da área. A partir de 2012, a Feira passou a premiar com o BolognaRagazzi Digital Award os mais inovadores exemplos de publicação de narrativas em mídia interativa para crianças. Organizado em parceria com a Children's Technology Review (Estados Unidos), o prêmio é um destaque para as tendências contemporâneas em conteúdo digital infantil, aplicados em áreas de entretenimento e educação.
} 


\section{Multiletramentos: novas textualidades para novas práticas de leitura}

A sociedade contemporânea tem vivenciado inúmeras transformações, sobretudo com o surgimento de diferentes formas de utilização da linguagem pelas tecnologias digitais. As transformações tecnológicas das últimas décadas, proporcionadas pela globalização e pela popularização dos computadores pessoais e dos dispositivos eletrônicos móveis, têm apontado para mudanças no âmbito da linguagem, a qual passa a explorar uma seleta gama de recursos expressivos específicos do ambiente digital.

A esse respeito, Barton e Lee (2015) destacam que, com o surgimento das novas tecnologias digitais, a vida contemporânea está mudando em muitos aspectos e isso impacta sobremaneira as formas de ler, de escrever, de se expressar, e de ver e entender o mundo. "As pessoas combinam recursos semióticos de novas maneiras e inventam novas relações entre linguagem e outros modos de construção de sentidos." (BARTON; LEE, 2015, p. 33). É possível afirmar, com base em Xavier (2013), que os diversos sistemas de escrita, em especial o alfabético, quando superpostos a outras formas de enunciação - visual e sonora, por exemplo -, em um mesmo suporte de leitura são capazes de gerar outros modos enunciativos, tal como tem acontecido, recentemente, no ambiente digital.

A convergência digital possibilitou aos sujeitos realizar múltiplas funções e ampliou as possibilidades de significação por meio dos textos com multiplicidade de linguagens e pela digitalização de sentidos. Nesse contexto, a linguagem migrou do caráter monomodal (ou monossemiótico) para o multimodal (ou multissemiótico). Tal migração possibilitou a convergência de mídias e a interação de linguagens: "[...] a linguagem existe como um conjunto de recursos que as pessoas utilizam para criar sentido de uma forma multimodal." (BARTON; LEE, 2015, p. 94).

A multimodalidade implica o uso de vários modos de representação para expressar sentidos em textos de variados gêneros na modalidade oral e escrita por meio das potencialidades das tecnologias digitais. Os modos, no entendimento de Kress (2010), são recursos semióticos constituídos socialmente e culturalmente para a construção de sentidos, originando-se, pois, a partir de práticas sociais significativas no contexto cultural em que são produzidas. Em outras palavras, significa dizer que os recursos semióticos podem ser diferentes em cada grupo social, sendo moldados, selecionados e transformados pela sociedade no decorrer dos anos e apresentam diferentes potenciais de representação para cada grupo em cada contexto de uso.

Tal fenômeno implica novas identidades para os textos da era atual que deixam de ter o predomínio da fala ou da escrita (modalidade verbal) para passarem a expressar o sentido em uma combinação de vários modos de representação por imagens estáticas e em movimento (fotos, ilustrações, grafismos, vídeos, animações - modalidades visuais), áudio (música e outros sons não verbais - modalidade sonora), linguagem corporal (gestualidade, danças, performances - modalidade gestual), e o espaço da página e das telas digitais (COPE; KALANTZIS, 2010; KRESS, 2010).

Com isso, novas são as formas de mobilizar conhecimentos no processo de compreensão de textos orais e escritos, pois os meios multimodais utilizados são alternativas diferentes que, em combinação, expressam o sentido por meio da sinestesia (KALANTZIS; COPE, 2012).

Em síntese, com o advento da cibercultura, as práticas sociais linguageiras geraram uma crescente demanda por letramentos que considerem os diversos modos de enunciação. Consequentemente, a formação de leitores capazes de se apropriarem dos textos produzidos e disponibilizados digitalmente demanda multiletramentos, os quais deverão abarcar variadas práticas e usos que envolvem tal fenômeno. 
O termo/conceito multiletramentos advém do conceito de letramento e foi cunhado a partir de estudos relativos ao entendimento dos processos e práticas de letramento em diferentes comunidades e grupos sociais. $\mathrm{Na}$ contemporaneidade, presencia-se a uma redefinição na concepção de letramento em virtude de duas dimensões: em primeira instância, a diversidade de sistemas semióticos e de modalidades de comunicação e, por conseguinte, a diversidade linguístico-cultural trazida pelos sujeitos nas práticas letradas (KLEIMAN; SITO, 2016).

$\mathrm{Na}$ década de 1980, pesquisadores como Street, Barton, Ivanic, Hamilton e Gee dedicaram-se a estudar as práticas sociais de leitura e escrita mais amplas do que a codificação e decodificação ("alfabetização"), ressaltando seus aspectos ideológicos. Esse movimento acadêmico de descoberta e de discussão de tais práticas situadas que envolvem a leitura e a escrita denominou-se New Literacy Studies (Novos Estudos do Letramento) (STREET, 2012).

A partir desses estudos, verifica-se, nos anos conseguintes, o surgimento de uma variedade de termos usados em relação ao letramento, tais como "eventos de letramento", "práticas de letramento", "modelos de letramento" (autônomo e ideológico), "letramento dominante" e "letramento vernacular" . Essas abordagens apontaram "para a heterogeneidade das práticas sociais de leitura, escrita e uso da língua/linguagem em geral em sociedades letradas." (ROJO, 2009, p. 102).

Por conseguinte, houve uma ampliação na variedade de expressões relacionadas ao termo, tais como letramento visual, letramento eletrônico, letramento digital, letramentos críticos, letramentos sociais, letramento literário, multiletramentos, entre outros. Essa amplitude na expressão identifica a variação, no tempo e no espaço, das diferentes tendências e relações de configuração das práticas de leitura e de escrita nas sociedades letradas.

"Nesse movimento, o conceito de letramento passa a ser plural: letramento $S$ " (ROJO, 2009 , p. 102, grifos da autora), os quais tem uma natureza sociológica e antropológica e está sempre associado a um sentido de identidade social que os sujeitos praticam ao construir a vida social. Conforme Soares (2002), o uso do plural "letramentos" enfatiza a ideia de que diferentes tecnologias de escrita geram diferentes condições naqueles que utilizam dessas tecnologias, em suas práticas de leitura e de escrita: "diferentes espaços de escrita e diferentes mecanismos de produção, reprodução e difusão da escrita resultam em diferentes letramentos." (SOARES, 2002, p. 156, grifos da autora).

$\mathrm{Na}$ contemporaneidade, constata-se o aparecimento do termo/conceito "multiletramentos", em especial, entre os defensores da concepção "social" da leitura e da escrita. Esse termo foi cunhado em 1996 pelo New London Group (Grupo de Nova Londres) pesquisadores da Austrália (Bill Cope, Mary Kalantzis, Allan Luke, Carmen Luke e Martin Nakata), dos Estados Unidos (Courtney Cazden, James Gee e Sarah Michaels) e do Reino Unido (Norman Fairclough e Gunther Kress) -, que se reuniu em 1994, em New London (estado de New Hampshire), Estados Unidos, para discutir novas propostas pedagógicas para o trabalho com letramentos emergentes na sociedade contemporânea, advindos, sobretudo, das tecnologias digitais. Para esses estudiosos, os diversos grupos socioculturais, sobretudo as crianças em idade escolar, recorrem a variados sistemas semióticos em complementação ou substituição às funções antes desempenhadas pela escrita alfabética, para atender às demandas comunicacionais.

Tomando a tela como espaço de escrita e de leitura, por exemplo, constata-se não apenas novas formas de acesso à informação, mas também novos processos cognitivos, novas

\footnotetext{
${ }^{4}$ Dados os limites e objetivos desta pesquisa, esses conceitos-chave dos Novos Estudos do Letramento amplamente descritos, discutidos e exemplificados em Kleiman (1995), Rojo (2009) e Street (2012) -, não são aqui discutidos.
} 
formas de conhecimento, novas maneiras de ler e de escrever, enfim, novos letramentos, isto é, novos estados para aqueles que exercem práticas de escrita e de leitura na tela.

Logo, não basta ao sujeito ser letrado para ler e escrever, é preciso desenvolver múltiplos letramentos para os textos que incorporam uma nova identidade pelas múltiplas representações de significado em sua composição na página impressa ou na tela do computador para a compreensão oral e escrita (COPE; KALANTZIS, 2009a). Tais procedimentos exigem o desenvolvimento de diferentes habilidades, fazendo emergir os estudos relacionados aos múltiplos (e novos) letramentos - informacional (busca e uso críticos da informação), visual (uso das imagens), digital (uso das tecnologias digitais), entre outros - ou os multiletramentos.

O foco de uma pedagogia para os multiletramentos recai não somente no modo linguístico, mas em outros meios de comunicação para complementá-lo, tendo em vista a comunicação por meio de textos impressos e digitais pelos seus leiautes multissemióticos forjados pelas potencialidades das tecnologias. Cope e Kalantzis (2010) discutem as mudanças sociais que geraram as novas mídias na contemporaneidade por meio de um estudo comparativo com as mídias tradicionais, levando em consideração quatro dimensões: agência, divergência, multimodalidade e conceituação.

A Dimensão 1, da agência (agency), equivale ao equilíbrio no uso das novas mídias, as quais fazem parte de uma equação mais ampla, de mudança social influenciada pela tecnologia. Enquanto mídias anteriores possuíam função apenas de transmissão, as mídias digitais são mais interativas, em que espectadores se tornaram usuários e leitores e ouvintes são convidados a se tornarem co-designers. Nessa concepção, rompe-se a divisão de trabalho entre criadores de conhecimento e consumidores, pois os sujeitos têm o poder de influenciar o curso da história, a responsabilidade passa a ser do indivíduo e do grupo ao qual ele pertence, e a diversidade ganhou espaço (COPE; KALANTZIS, 2010).

A Dimensão 2, divergência (divergence), trata da diversidade material, corporal e simbólica que fica em evidência a partir do espaço criado para a agência. Todas elas encontram-se presentes no cotidiano pessoal, profissional, escolar. A agência transforma a lógica da uniformidade em uma lógica da diferença. Nesse âmbito, as novas mídias são um dos muitos catalisadores na transição de uma era de homogeneização para uma era de divergência. Isso ocorre porque as novas mídias fornecem canais para que as diferenças se representem. Depois de uma era em que toda pressão era criar homogeneidade (mídia de massa, autores best-sellers, produtos produzidos em massa, assimilação de minorias), a sociedade e a mídia hodiernas oferecem espaços para a divergência (a miríade de oportunidades de publicação na Web, de redes sociais online, refletindo todo e qualquer tom de identidade e timbre de voz) (COPE; KALANTZIS, 2010).

A multimodalidade (multimodality) consiste na Dimensão 3. O mundo digital reduz a unidade elementar para a produção de sentido textual do caractere para o pixel. Simplificadamente, isso significa que a linguagem escrita, o som e a imagem são feitos do mesmo material. As tecnologias digitais possibilitam a conjugação de diferentes formas de representação: as imagens com o áudio, o áudio com a escrita, entre outros. Os dispositivos digitais armazenam, sobrepõem e distribuem esses compostos, constituindo a multimodalidade, isto é, a capacidade de misturar modos. Novas literacias centradas em textos híbridos e multimodais surgem. Modos de significado que eram relativamente separados tornam-se cada vez mais interligados. As consequências práticas são enormes, à medida que o texto escrito aparece com maior frequência na mídia tradicionalmente visual e surgem mídias multimodais verdadeiramente integradas, mesmo em áreas clássicas como a impressão (COPE; KALANTZIS, 2010).

A Dimensão 4 diz respeito à conceituação (conceptualisation) ou sensibilidade "conceitualizadora", requerida pelas novas mídias. Antigamente, o usuário não precisava 
saber muito sobre a máquina. Na atualidade, não basta ao usuário ser apenas um espectador/leitor/consumidor, mas exercer domínio sobre as novas arquiteturas sociais e técnicas (COPE; KALANTZIS, 2010).

Diante desse cenário de transformações, entende-se que se os textos contemporâneos mudaram, as competências de leitura e produção textual exigidas aos sujeitos para participar de práticas de letramentos atuais também suscitam atualização. "A lógica dos multiletramentos é aquela que reconhece que a criação de sentido é um processo ativo, transformador." (COPE; KALANTZIS, 2009a, p. 175, tradução nossa).

Portanto, Kalantzis e Cope (2000) explicitam a necessidade de compreensão dos "Designs de futuro" (relações com as práticas de letramentos escolares) que considerem três dimensões da vida contemporânea nas sociedades globalizadas: a da diversidade produtiva (no âmbito do trabalho - multicapacitação e autonomia; flexibilidade para adaptação à mudança); a do pluralismo cívico (no âmbito da cidadania - "coesão-pela-diversidade"; ampliação dos repertórios culturais); a das identidades multifacetadas (no âmbito da vida pessoal - culturas híbridas; consciência descentrada).

A propósito, o principal eixo estruturante da teoria dos multiletramentos é o conceito de "design" de sentidos, pois é a partir dele que a teoria instanciará as concepções de agenciamento, multimodalidade e produção de sentido, essenciais para o ensino requerido na contemporaneidade. De acordo com Cope e Kalantzis (2009a), ao desenvolver os conceitoschave para uma pedagogia dos multiletramentos na década de 1990, o Grupo de Nova Londres, com o intuito de se contrapor a conceitos tradicionais pautados na visão estática e monomodal da linguagem (sobretudo, a escrita), estabeleceu a concepção "design", palavra que possui duplo e fortuito significado, descrevendo simultaneamente estrutura (sistemas, formas e convenções de sentido) e ato de produção de sentido (processo criativo pelo qual o sujeito, enquanto produtor de sentido, torna-se designer e agenciador de sentidos e não simples receptor de habilidades e competências). Assim, o design se estabelece no processo de representação de significados, para o próprio sujeito em processos de tomada de sentido, como ler, escutar ou ver, ou para o mundo em processos comunicativos como escrever ou falar.

Cope e Kalantzis (2009a) indicam que, na perspectiva dos multiletramentos, o processo do design é composto por três aspectos: availables designs (designs disponíveis): recursos culturais e contextuais com o propósito específico de possibilitar a produção de sentido, que compreendem o modo de significação (verbal, visual, áudio, gestual, táctil e espacial), o gênero (a forma que um texto tem) e o discurso (a forma como o sentido é produzido em uma instituição social); designing: o processo de produção de sentido e a recontextualização da representação do mundo por meio dos available designs; redesigned: o mundo transformado em novos available designs, que instanciam novos sentidos. Esses aspectos são essencialmente culturais e ideológicos, uma vez que estão relacionados a visões de mundo de diferentes sujeitos em contextos diversificados.

O entendimento do New London Group (2000, p. 20, tradução nossa) de design como "qualquer atividade semiótica, incluindo a utilização da língua para consumir e produzir textos" por meio dos três processos supracitados, aproxima-se da proposta do Círculo de Bakhtin de que:

$\mathrm{Na}$ maioria das vezes a psicologia social se realiza nas mais diversas formas de enunciados, sob o modo de pequenos gêneros discursivos, sejam eles internos ou externos [...]. Todos esses discursos verbais estão correlacionados, é claro, com outros tipos de manifestação e interação por meio de signos: com a expressão facial, a gesticulação, os atos convencionais e assim por diante. Todas essas formas de interação discursiva [...] reagem com extrema sensibilidade a todas as oscilações do meio social. 
Volume 14 - Número 2 - ago/dez de 2019

[...] É necessário estudar a psicologia social sob dois ângulos: primeiramente, do ponto de vista de seu conteúdo, ou seja, sob o prisma dos temas que são pertinentes a ela em algum momento; e, em segundo lugar, do ponto de vista das formas e tipos de comunicação discursiva em que esses temas se realizam [...]. (VOLÓCHINOV, 2017, p. 107-108, grifos do autor).

Conforme Oliveira e Szundy (2014), essa aproximação ocorre no entendimento de que os designs para o Grupo de Nova Londres e os gêneros do discurso para o Círculo de Bakhtin são constantemente reatualizados e redesenhados a partir das atitudes responsivas de comunidades específicas em momentos históricos situados, considerando que a filosofia da linguagem do Círculo de Bakhtin "está imbuída da leveza de pensamento e plasticidade necessárias para compreensão e análise das práticas de multiletramentos na contemporaneidade." (OLIVEIRA; SZUNDY, 2014, p. 184).

O projeto dos multiletramentos do Grupo de Nova Londres propõe uma grade analítica para cinco modalidades (modos de significação) e seus elementos de design (NEW LONDON GROUP, 2000; COPE; KALANTZIS, 2009b):

a) design linguístico: inclui elementos de significação linguística, como vocabulário, transitividade, nominalização de processos, estrutura informacional, relações de coerência global e local, entre outros. Pode ser dividido em língua escrita - escrita (representando significado para o outro) e leitura (representando significado para si mesmo) - e linguagem oral - fala ao vivo ou gravada (representando significado para o outro) e ouvindo (representando significado para si mesmo);

b) design visual: imagem parada ou em movimento, escultura, artesanato (representando significado para o outro); ver, vista, cena, perspectiva (representando o significado para si mesmo). Inclui elementos de significação visual, tais como cores, perspectiva, vetores, figura e fundo, entre outros;

c) design sonoro: música, sons ambientes, ruídos e alertas (representando o significado para o outro); ouvir e escutar (representando o significado para si mesmo);

d) design gestual: movimentos das mãos e braços, expressões do rosto, movimentos oculares e olhar, comportamentos do corpo, roupas e moda, estilo de cabelo, dança, sequências de ação, rituais e frequência. Aqui, o gesto é entendido, ampla e metaforicamente, como um ato físico de assinatura, ao invés do significado literal mais restrito de movimento de mão e braço. Inclui ainda a representação tátil: toque, olfato e paladar: a representação de si mesmo das sensações e sentimentos corporais ou representações para os outros que os "tocam" corporalmente. Formas de representação tátil incluem cinestesia, proxêmica, contato físico, sensações de pele, aromas, objetos manipuláveis, artefatos;

e) design espacial: proximidade, espaçamento, leiaute, distância interpessoal, territorialidade, arquitetura/construção, paisagens, significação geográfica.

Trata-se, portanto, da expansão do conceito de linguagem para outros sistemas representacionais e outros modos comunicacionais, para a elaboração de significados utilizados dentro de cada cultura. Nesse sentido, cabe salientar que a proposta pedagógica dos multiletramentos não constitui o abandono do código escrito - cuja construção também suscita leitura multimodal em detrimento de sua estrutura composicional, como formatos, tamanhos e cores de letras -, mas sim, a expansão da forma de alfabetização para além da alfabética, com vistas a atender aos fundamentos da configuração de textos multimodais (KALANTZIS; COPE, 2012).

Nessa perspectiva, o uso de ambientes multimodais de aprendizagem e a assimilação de projetos multiculturais tornam-se fundamentais para a composição de uma nova identidade 
para o ensino concebido como práticas para os multiletramentos. A criação do espaço da tela, por exemplo, demanda a utilização do conjunto de recursos multimodais, além de uma ênfase na tipologia e em seus efeitos para expressar sentido. Logo, esse processo cíclico do design suscita a criatividade, o dinamismo, a inovação, o interesse e a motivação dos produtores de sentidos.

Conforme apontado por Menegazzi (2018), as interfaces dos Livros Literários Infantis digitais interativos em formato de Aplicativos (LLIA) são compostas simultaneamente por muitas mídias em diferentes modos sensoriais, isto é, são multimodais. Os LLIA possuem como principal característica a combinação de diferentes mídias (ou modos) dentro de uma única interface, conectados entre si por diversas formas de interatividade.

Torna-se relevante, portanto, a discussão das transformações que as tecnologias digitais provocam nas concepções do livro de literatura infantil, e como essas mudanças propiciam novas formas, tempos e espaços de leitura, considerando o uso cada vez mais precoce de dispositivos móveis de interação por parte das crianças, aliada à incipiente produção de LLIA

Na próxima seção, apresenta-se a descrição do percurso metodológico assumido por este estudo, com o intuito de detalhar a delimitação dos dados da pesquisa.

\section{0 percurso metodológico}

Trata-se de pesquisa qualitativa, que utiliza métodos de investigação de base interpretativista, pois busca a interpretação de fenômenos e a descrição de significados por meio de análise indutiva e visa à descrição, compreensão e explicação das relações entre o global e o local em determinado fenômeno e o respeito ao caráter interativo entre os objetivos buscados, suas orientações teóricas e seus dados empíricos (MINAYO, 2001). As pesquisas que focalizam os Letramentos, por sua preocupação com questões sociais e por seu interesse voltado para os usos reais das linguagens, têm adotado metodologias de caráter qualitativointerpretativista (MOITA LOPES, 1996).

Delimitou-se como corpus de pesquisa uma obra criada exclusivamente para o meio digital: "Wuwu \& Co.", vencedora do BolognaRagazzi Digital Award de 2016, como melhor ficção digital. Escrito por Merete Pryds Helle e ilustrado por Kamila Slocinska, este LLIA foi lançado em 2015 pela editora dinamarquesa Step In Books, e funciona em diferentes dispositivos nos sistemas operacionais móveis iOS (Apple) e Android (Google).

A leitura dos textos contemporâneos exige tanto conhecimentos dos dispositivos móveis de interação e dos mecanismos de navegação pelos ambientes hipermidiáticos, quanto habilidades de busca e compreensão das informações almejadas. Nesses procedimentos, o leitor/agenciador lida com percursos e possibilidades que demandam estratégias de escolhas frente ao encontro com uma profusão de tipografias, imagens, animações, vídeos, sons, hiperlinks, leiautes e formatos diversos.

Serafini (2010) propõe um modelo para a análise de livros de literatura infantil impressos a ser usado na promoção do letramento multimodal, e que, com as colaborações de Frederico (2016), pode igualmente ser aplicado a textos digitais como os presentes nos LLIA. Esse modelo está estruturado em três níveis (perceptivo, estrutural, ideológico): perceptivo (nível mais básico de análise, em que o enfoque se dá no sentido literal dos signos. Em termos didáticos, significa olhar em detalhe para os signos que compõem o texto, identificar, elencar e nomear esses elementos); estrutural (nível em que se analisa a gramática funcional das diversas modalidades que compõe o texto, ou como as estruturas das modalidades verbal, visual, sonora, etc., fazem com que esses elementos possuam determinados sentidos. Nesse nível, são também consideradas as relações entre as diferentes modalidades ou relações intermodais); ideológico (nível em que são analisados os contextos sociocultural, histórico e 
político em que os textos foram criados e em que são lidos. Essa discussão inclui o processo de criação e distribuição dos textos e a análise crítica das representações presentes nesse texto, abordando questões raciais, de gênero, distribuição de poder e estereótipos, por exemplo.

Quanto aos aspectos relacionados com a qualidade textual (verbo-viso-sonora) e da narrativa multimodal em LLIA, Yokota e Teale (2014) propõem as seguintes observações: a apresentação da narrativa em formato digital é adequada?; os recursos interativos mantêm a integridade da narrativa?; os recursos suplementares estão alinhados com a narrativa?; a história é bem contada, de acordo com padrões literários?; a história aproveita, de forma adequada, os recursos permitidos pelo mundo digital, para além do que é possível no impresso?; todos os recursos fazem sentido ao aprendizado da leitura e do conteúdo em termos gerais?; a linguagem do texto escrito é bem elaborada?; as ilustrações são artísticas? Elas dialogam bem com o texto escrito para iluminar, ampliar e/ou cocriar a narrativa como um todo?

Diante desses questionamentos catalisadores, percebe-se que as diferentes textualidades apresentam desafios aos letramentos e às teorias da leitura, devido à multiplicidade de linguagens, semioses e mídias envolvidas no processo de produção de sentido, além da diversidade cultural trazida pelos sujeitos nas práticas de leitura.

Apresenta-se, na sequência, uma amostra da ocorrência de agenciamentos e interações multimodais no LLIA "Wuwu \& Co." - associada aos elementos narrativos e estruturais que mobilizam práticas multiletradas de leitura.

\section{Apresentação e discussão dos resultados}

\subsection{Descrição do LLIA “Wuwu \& Co.” e análises empreendidas}

"Wuwu \& Co." é um aclamado LLIA que combina uma narrativa literária instigante e recursos interativos de uma forma que requer que o leitor infantil se torne um cocriador da narrativa de diversas maneiras. A obra que impressionou os jurados do BolognaRagazzi nos quesitos da usabilidade, da estética e das técnicas inovadoras de interação, apresenta as aventuras de cinco criaturas (Wuwu, Thit Maya, Everett, Pruney e Storm), peculiares em suas formas e cores, que necessitam da ajuda do leitor/agenciador em desafios durante o inverno.

Com a presença de realidade aumentada, ambientes virtuais imersivos e animações (automáticas ou ativadas por meio do toque na tela), utiliza recursos de giroscópio (visão $360^{\circ}$ ), acelerômetro, câmera e microfone, aplicando-os a desafios, simulando um jogo em primeira pessoa, em que o leitor ora vê pelos olhos das personagens, ora é colocado diante do universo que o cerca, movimentando-se em seu espaço físico sem tirar a atenção da tela, na tentativa de localizar as personagens e os cenários apresentados.

Indicada para crianças de 6 a 8 anos, a obra é agradável tanto ao público ao qual é endereçado quanto para crianças maiores, sendo cativante até para jovens e adultos. Acreditase que leitores menos experientes possam necessitar da mediação de um adulto em alguns momentos da leitura no modo "Eu leio", em virtude da considerável quantidade de texto escrito, dividido em sete capítulos - introdução, histórias das cinco personagens (conflito) e desfecho. Está disponível em cinco idiomas: inglês, francês, alemão, espanhol e dinamarquês. Excepcionalmente, o português não foi contemplado, fato que pode comprometer o pleno entendimento das narrativas por considerável parcela de crianças leitoras brasileiras.

Há a presença de um narrador apenas para o texto verbal escrito, uma vez que as personagens protagonistas têm falas próprias e "conversam" com o leitor. Os recursos de giroscópio e acelerômetro constituem em diferenciais dessa obra, pois possibilitam ao sujeito, quando solicitado, inclinar, chacoalhar, mudar a posição vertical/horizontal e até virar o dispositivo de cabeça para baixo. A história aproveita adequadamente todos os recursos 
permitidos pelo mundo digital, extrapolando as possibilidades da leitura impressa. Quando acionada pela primeira vez, a história se inicia a partir da leitura (ou narração) de um texto em que o leitor é introduzido ao plano geral do enredo, que revela o seguinte: o inverno mais rigoroso em dois mil anos chegou e toda a floresta já está congelada. As árvores parecem gigantes pingentes de gelo e o sol está pendurado acima das nuvens como um disco pálido. Há apenas um lugar em toda a floresta que é quente e aconchegante, o interior da Little Red House (Pequena Casa Vermelha), onde há uma lareira acesa - fato constatado pela ilustração da casa cuja chaminé solta nuvens de fumaça, localizada entre o título da história e o texto verbal escrito. A partir de então, o leitor passa a fazer parte da narrativa, uma vez que é mencionado por meio de texto verbal que "ele não é o único que pensa que assim", isto é, que outros sujeitos também sabem que a casa vermelha no centro da floresta consiste no melhor refúgio no inverno. Na tela seguinte, o leitor descobre que está sozinho no interior da pequena residência, e que, para olhar ao redor da sala de estar, necessita inclinar seu livro digital. Ao realizar essa ação, o leitor é transportado para dentro da casa, de maneira imersiva, por meio de realidade virtual.

Conforme retrata a Figura 1, ao passo em que, numa visão em $360^{\circ}$, explora a aconchegante sala de estar e os demais cômodos, em que poucos elementos possuem coloração, percebe um vozerio vindo da parte externa, o qual se confunde com os relaxantes sons internos provenientes, respectivamente, da música que toca no gramofone e do crepitar das chamas do fogo da lareira. Repentinamente, escutam-se batidas na porta azul da sala e as vozes das criaturas indicando que estão cansados, com frio e fome, e que necessitam adentrar o recinto. Para tanto, indicam ao leitor/agenciador, a existência de uma chave pendurada em algum lugar da sala, a qual destrancará a porta. Uma vez aberta a porta, as criaturas adentram a residência, agradecem ao leitor e iniciam os seus murmúrios. Posicionadas em diferentes pontos da sala, dispostas em círculo, cada uma delas tem um discurso diferente, na qual apresentam um problema para o leitor, que possui autonomia para escolher a qual ajudará primeiro. Para resolvê-los, é necessário realizar a leitura/audição da história da personagem escolhida para então interagir de maneira distinta nos desafios propostos, os quais são realizados fora da casa. Caso o leitor seja bem-sucedido, a personagem agradece e este retorna ao ponto de partida, a casa vermelha, onde pode ler/ouvir a história da próxima personagem e ajudá-la a resolver seu problema.

Figura 1 - Telas iniciais do LLIA "Wuwu \& Co."

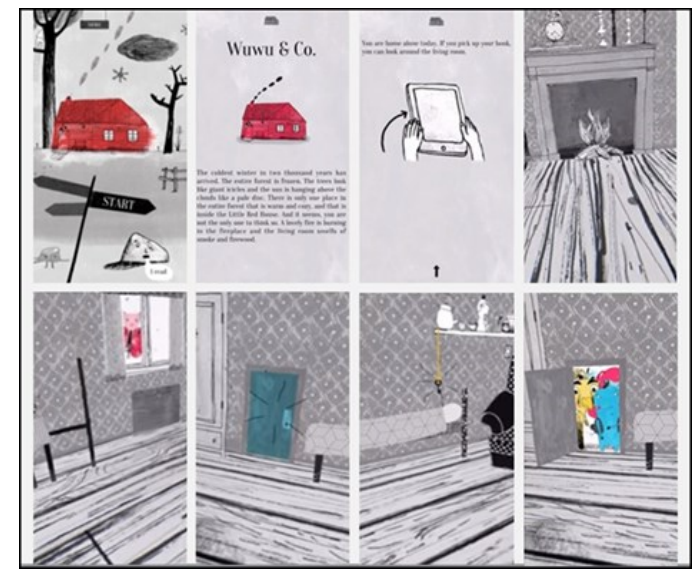

Fonte: HELLE; SLOCINSKA (2015).

A leitura das histórias de cada uma das cinco personagens (texto predominantemente verbal) se passa dentro da casa vermelha e é possibilitada quando o dispositivo é colocado na posição horizontal, deitado ou não sobre uma superfície. A linguagem verbal apresenta-se de 
Volume 14 - Número 2 - ago/dez de 2019

modo similar aos livros de literatura infantis e juvenis impressos, com pequenos e médios parágrafos formados por frases curtas, apresentadas em alto contraste e sem variação de cor/textura, associadas ou não a ilustrações na mesma página/tela, que podem ser lidas/ouvidas de maneira contínua. Cada parágrafo apresenta uma ideia-núcleo, em que os tópicos frasais são enunciados em escrita poética. Normalmente, o último parágrafo, um pouco mais curto que os demais, indica ao leitor a maneira correta de auxiliar as personagens em suas problemáticas. A linguagem do texto escrito por Merete Pryds Helle é bem elaborada e as ilustrações (imagens estáticas e em movimento) de Kamila Slocinska são artísticas, dotadas de pregnância estética e dialogam bem com o texto escrito para ampliar e cocriar a narrativa como um todo (Figura 2).

Figura 2 - Apresentação da história do personagem Storm, em "Wuwu \& Co."

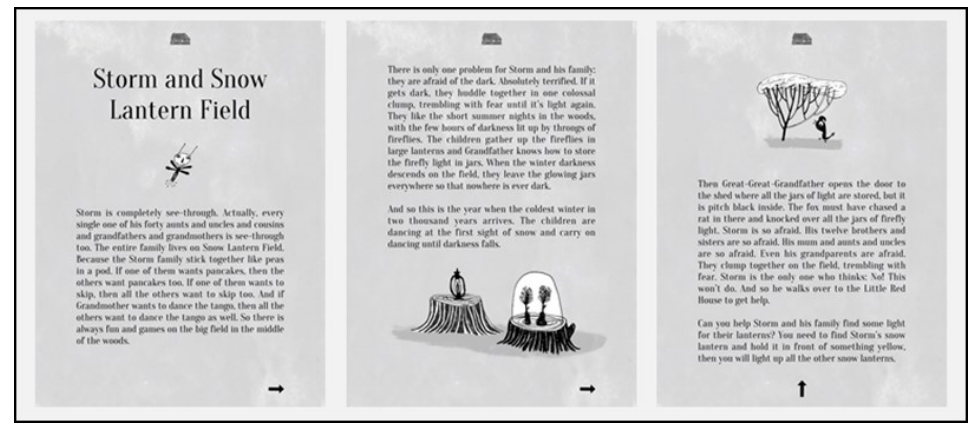

Fonte: HELLE; SLOCINSKA (2015).

Ao final da leitura, na última página/tela de texto escrito, enquanto o dispositivo não é colocado novamente na posição vertical pelo leitor/agenciador, o narrador (se estiver acionado) lembra-o insistentemente da necessidade da realização dessa ação para a continuidade da história/cena: "You can always just lift the book and look around" ["Você pode simplesmente levantar o livro e olhar em volta"]. Ao mesmo tempo, uma seta localizada na parte inferior da tela sinaliza a direção em que o leitor deve movimentar o dispositivo (para cima). Contudo, caso o leitor o posicione o dispositivo na vertical antes de terminar a leitura, ocorrerá transição abrupta para o ambiente externo, promovendo a ruptura no entendimento da linearidade da narrativa. Com exceção desse detalhe, há manutenção da integridade da narrativa frente aos recursos interativos disponibilizados pela obra.

O leitor/agenciador se apropria do texto literário por meio de três modelos de narrativas: cumulativas, circulares e encadeadas. Tanto no texto introdutório como nas cinco histórias, há a menção do fio condutor da narrativa, que consiste na chegada do inverno mais rigoroso dos últimos dois mil anos. Em contrapartida, cada uma das personagens enfrenta uma dificuldade na localidade da densa e vasta floresta em que residem, fazendo com que procurem por ajuda na Pequena Casa Vermelha, fato que ocasiona o encontro das cinco. Portanto, o leitor compreende que as criaturas vivem separadamente apenas quando inicia a leitura de alguma das histórias. À medida que as histórias são lidas e os desafios são completamente realizados, a sala de estar da casa vermelha ganha um quadro com uma pintura/fotografia das personagens ajudadas. Ao término das cinco leituras/desafios, um grande quadro retangular com a pintura das cinco criaturas aparece na parede central da sala de estar. É a partir desse quadro e dos quadros menores que o leitor poderá realizar novamente as leituras e interagir com as personagens na próxima vez que ligar o aplicativo, tendo como ponto inicial de acesso o menu Continue (Continuar).

Constatou-se que as histórias dessas personagens são verossímeis, pois, por meio da linguagem literária, plasmam experiências reais tanto de humanos quanto de animais selvagens, principalmente daqueles que habitam as regiões polares do planeta Terra, ou 
aqueles em que os invernos são extremamente intensos, possibilitando ao leitor a expansão da experiência de leitura por meio da vivência dos dramas das personagens, sem deixar de se divertir na execução das tarefas interativas.

"Wuwu \& Co." é um LLIA primoroso por retratar, frugalmente, a inclusão, a solidariedade, as mazelas e, principalmente, a diversidade. No clímax da obra, os protagonistas resgatam uma harmonia ainda maior do que a que havia no início da narrativa, por meio de gestos de partilha, bom convívio, de interação entre seres com capacidades e habilidades tão peculiares. A Figura 3 evidencia que o texto escrito presente na primeira tela de "Wuwu \& Co." - "A lovely fire is burning in the fireplace and the living room smells of smoke and firewood" ["Um fogo adorável está queimando na lareira e a sala de estar cheira a fumaça e lenha"] - dialoga diretamente com o ambiente de imersão em 3D (o interior da casa), em que o som emitido pelo crepitar das chamas na lareira, aliado ao tom acinzentado da sala de estar, dá ao leitor/agenciador a sensação de que o ambiente está realmente cheirando a lenha queimada. A mensagem passada pelo texto escrito ajuda o leitor/agenciador a iniciar a exploração no interior da casa, que possui uma série de elementos multimodais.

Figura 3 - Função de ligação do texto verbal escrito em "Wuwu \& Co.".

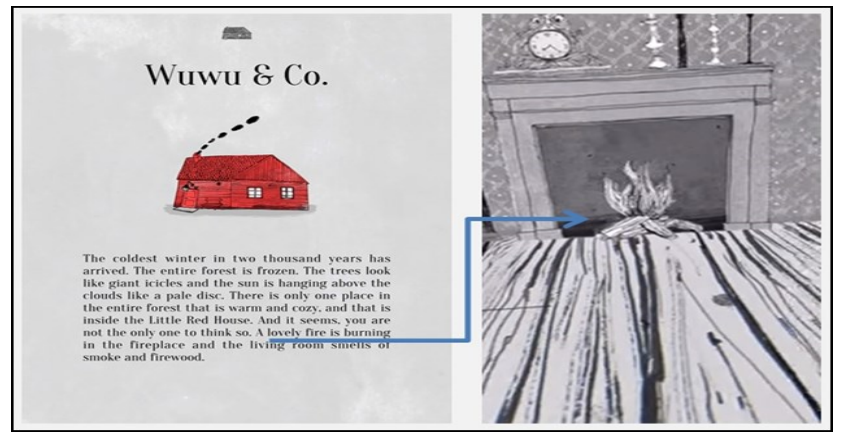

Fonte: HELLE; SLOCINSKA (2015).

Em "Wuwu \& Co.", verificam-se três formatos de animação: as completamente automáticas, as ativadas/desativadas pelo leitor/agenciador e as mistas (automáticas com a intervenção do leitor). Todas as histórias da obra possuem animações bem constituídas espaço-temporalmente, em que as personagens realizam diferentes ações que potencializam as narrativas. A personagem Wuwu, por exemplo, em sua aventura pelo mar, logo após afugentar o tubarão com o auxílio do leitor/agenciador, rema em direção à praia, cantarolando o refrão de My Bonnie Lies over the Ocean, uma música do folclore escocês que permanece popular na cultura ocidental. Por meio dos sofisticados recursos imersivos de animação e de interação, o leitor tem a sensação de estar junto de Wuwu em seu barco navegando pelas nuances do mar cinzento (Figura 4).

Figura 4 - Animação em "Wuwu \& Co.”

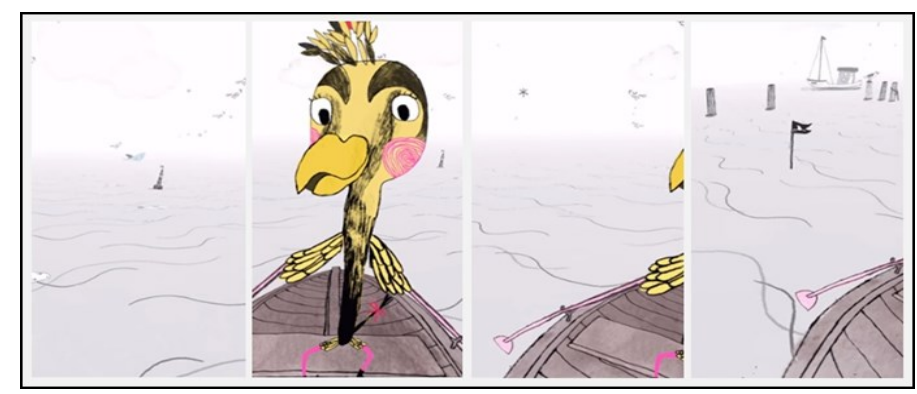

Fonte: HELLE; SLOCINSKA (2015). 
A obra apresenta trilha sonora composta por vozes das personagens principais e do narrador, efeitos sonoros, ruídos mnemônicos e músicas diegéticas e não-diegéticas que acompanham as narrativas. Em diversos momentos das histórias, predomina o silêncio, isto é, a ausência total ou relativa de sons audíveis. Os exemplos de trilha sonora que se destacam são: o crepitar do fogo da lareira no interior da casa vermelha; a música clássica emitida pelo gramofone na sala da casa; os sons característicos advindos da floresta (vento soprando, uivos, balançar dos galhos das arvores, o tilintar dos flocos de neve caindo, entre outros); a cantiga alegre proferida por Wuwu enquanto veleja no mar. Há ainda a possibilidade de gravação da voz e incorporação desta ao aplicativo apenas no cenário da personagem Everett (Figura 5), em que o leitor/agenciador precisa gritar ou falar alto ao microfone para acordar os Everetts no alto de uma árvore, para que consigam se refugiar do frio ainda mais rigoroso que se aproxima. Assim que são acordados, os três grupos de Everetts passam a repetir aquilo que foi pronunciado pelo agenciador.

Figura 5 - Interação por voz em "Wuwu \& Co."

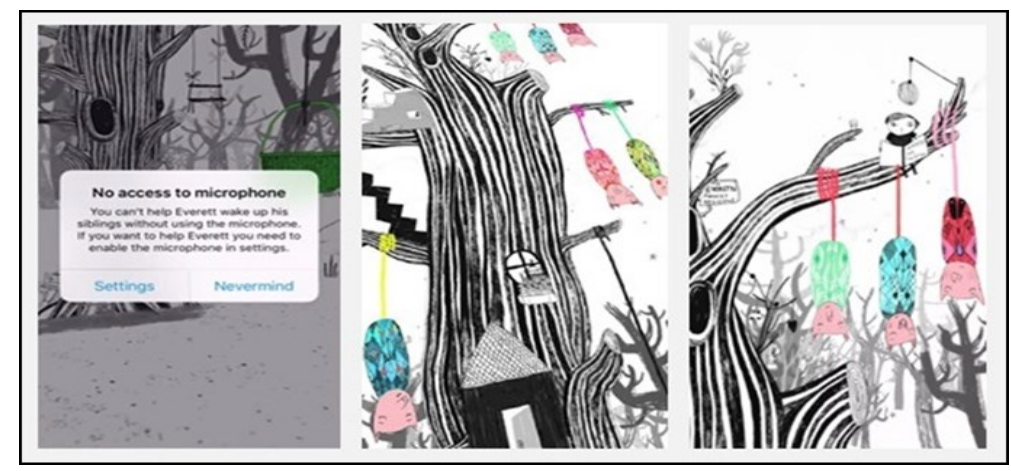

Fonte: HELLE; SLOCINSKA (2015).

As páginas/telas de "Wuwu \& Co." podem ser viradas com o deslizar dos dedos assim como ocorre no impresso -, além de outras alternativas de transição, tais como o toque sobre setas e ícones nas partes inferior e superior da tela do dispositivo, acompanhadas ou não por ambientação sonora, animações e movimentações do dispositivo móvel. $\mathrm{O}$ leitor/agenciador navega instantaneamente de uma página/tela para outra, podendo, em certas situações, retornar ao menu inicial e selecionar o ambiente de preferência. Após a leitura, quando o sujeito posiciona o dispositivo na vertical, vê-se imerso na floresta em que as criaturas habitam, as quais o esperam para a realização dos desafios. Na cena em que a personagem Thit Maya solicita auxílio para derrubar as pinhas de um pinheiro para fazer uma sopa para ela e seus amigos, por exemplo, o leitor/agenciador deve movimentar o dispositivo rapidamente de forma a derrubá-las, como se estivesse chacoalhando a árvore. Verificou-se que as orientações sobre a maneira como o leitor deve proceder para realizar esse desafio também são evidenciadas por meio de texto verbal escrito, em forma de lembrete ao final da narrativa: "Can you help Thit Maya and her friends shake the pine tree? Remember what she said: First the snow has to be shaken off, and then the pinecones have to be shaken to the ground." ["Você pode ajudar Thit Maya e seus amigos a agitar o pinheiro? Lembre-se do que ela disse: primeiro a neve tem que ser sacudida, e então as pinhas têm que ser sacudidas até o chão.’].

\subsection{Síntese das análises}

Evidenciou-se que a obra selecionada mobiliza o corpo, variações recriadoras e movência. Neste LLIA, a interatividade exige a agentividade do leitor para fazer ligações 
entre objetos distintos, possibilitando movimentação deliberada por meio do conteúdo de forma não linear, diferentemente do livro impresso, que é basicamente linear, em que o leitor não pode interferir na narrativa literária.

Verificou-se que, em virtude de os gêneros textuais existirem em consonância com seus suportes, passam a se reorganizar de acordo com as funções que surgem nos novos objetos de leitura. Consequentemente, o leitor é impelido a reconfigurar suas relações com o artefato, disponibilizando-se a interagir ludicamente com interfaces multimodais (multi/hipermidiáticas). Na medida em que o sujeito lê/agencia, também é interpelado sobre questões relativas à sua corporeidade.

$\mathrm{A}(\mathrm{s})$ leitura(s) em telas multitouch mobilizam habilidades específicas no leitor, visto que novas estratégias são suscitadas para a produção de sentidos, considerando a articulação de diferentes linguagens. A combinação multimodal nos LLIA, aliada à agentividade dos sujeitos e às potencialidades das tecnologias digitais, aciona modos diferenciados de leitura e demanda maior interatividade por parte do leitor.

\section{Considerações finais}

A realização desta pesquisa possibilitou a compreensão das particularidades da leitura do texto de literário em telas de LLIA, principalmente no que se refere à relação do corpo do leitor/agenciador com os dispositivos móveis de interação, na perspectiva dos multiletramentos.

Verificou-se que a presença de múltiplas combinações multimodais/multissemióticas nos LLIA, aliada à agentividade do leitor e às potencialidades das tecnologias digitais, exige a necessidade de maior interatividade e aciona modos diferenciados de leitura que contribuem para a ampliação das possibilidades de produção de sentido.

Os sujeitos leitores são mobilizados pelas obras literárias em formato de aplicativo, e a leitura gera diferentes experiências. O leitor/agenciador infantil lida com percursos e possibilidades que demandam escolhas frente a uma profusão de tipografias, imagens, animações, vídeos, sons, hiperlinks, leiautes e formatos diversos. Manifestadas na corporeidade, a apropriação, ampliação, vivência e transformação dessas diferentes linguagens oportunizam significação e ressignificação do(s) texto(s) e do leitor.

A investigação demonstrou que a linguagem verbovisual em LLIA suscita adaptação, vislumbrando a exploração dos recursos digitais multi/hipermídia, assim como requer a mobilização de outros canais sensoriais por parte dos leitores, configurando-se, deste modo, como linguagem multissensorial.

Conforme já ocorre com textos literários impressos, verifica-se a existência da coautoria textual na interatividade com o LLIA, em que o leitor/agenciador, ao explorar os variados textos multissemióticos que o rodeiam, além de procurar compreendê-los e interpretá-los, ativa sua memória, inter-relaciona experiências e fatos, elabora inferências e, assim, produz sentidos (seus próprios textos).

\section{Referências}

BARTON, D.; LEE, C. Linguagem online: textos e práticas digitais. 1. ed. São Paulo: Parábola Editorial, 2015.

COPE, B.; KALANTZIS, M. "Multiliteracies": new literacies, new learning. Pedagogies: An International Journal, Singapura, v. 4, n. 3, p.164-195, ago. 2009a.

COPE, B.; KALANTZIS, M. A Grammar of Multimodality. The International Journal of Learning, Melbourne, v. 16, n. 2, p. 361-425, 2009 b. 
COPE, B.; KALANTZIS, M. New media, new learning. In: COLE, D. R.; PULEN, D. L. (Ed.). Multiliteracies in motion: current theory and practice. New York: Routledge, 2010. p. 87-104.

FREDERICO, A. O futuro do leitor ou o leitor do futuro: o livro infantil interativo e os letramentos múltiplos. Cadernos de Letras da UFF, Niterói, v. 26, n. 52, p. 101-120, jan./jun. 2016.

HELLE, M. P.; SLOCINSKA, K. Wuwu \& Co.: a magical picture book. Copenhague: Step in Books, 2015. Book app.

KALANTZIS, M.; COPE, B. Changing the role of schools. In: COPE, B.; KALANTZIS, M. (Ed.). Multiliteracies: literacy learning and the design of social futures. London; New York: Routledge, 2000. p. 121-148.

KALANTZIS, M.; COPE, B. Literacies. Cambridge: Cambridge University Press, 2012.

KLEIMAN, A. B. Modelos de letramento e as práticas de alfabetização na escola. In: KLEIMAN, A. B. (Org.). Os significados do letramento: uma nova perspectiva sobre a prática social da escrita. Campinas: Mercado de Letras, 1995. p. 15-61.

KLEIMAN, A. B.; SITO, L. R. S. Multiletramentos, interdições e marginalidades. In: KLEIMAN, A. B.; ASSIS, J. A. (Org.). Significações e ressignificações do letramento. 1. ed. Campinas: Mercado de Letras, 2016.

KRESS, G. R. Multimodality: a social semiotic approach to contemporary communication. New York; London: Routledge, 2010.

MENEGAZZI, D. L. O design de interfaces de livros infantis apps: uma revisão das características e recomendações. Textura, Canoas, v. 20, n. 43, p. 215-238, maio/ago. 2018.

MINAYO, M. C. S. Ciência, técnica e arte: o desafio da pesquisa social. In: MINAYO, M. C. S. (Org.). Pesquisa social: teoria, método e criatividade. 19. ed. Petrópolis: Vozes, 2001. p. 930 .

MOITA LOPES, L. P. Oficina de linguística aplicada: a natureza social e educacional dos processos de ensino/aprendizagem de línguas. Campinas: Mercado de Letras, 1996.

NEW LONDON GROUP. A pedagogy of multiliteracies: designing social futures. In: COPE, B.; KALANTZIS, M. (Ed.). Multiliteracies: literacy learning and the design of social futures. London; New York: Routledge, 2000. p. 9-37.

OLIVEIRA, M. B. F.; SZUNDY, P. T. C. Práticas de multiletramentos na escola: por uma educação responsiva à contemporaneidade. Bakhtiniana, São Paulo, v. 9, n. 2, p. 184-205, ago./dez. 2014.

ROJO, R. Letramentos múltiplos, escola e inclusão social. São Paulo: Parábola Editorial, 2009.

SERAFINI, F. Reading multimodal texts: perceptual, structural and ideological perspectives. Children's Literature in Education, v. 41, n. 2, p. 85-104, 2010.

SOARES, M. Novas práticas de leitura e escrita: letramento na cibercultura. Educação \& Sociedade, Campinas, v. 23, n. 81, p. 143-160, dez. 2002.

STREET, B. Eventos de letramento e práticas de letramento: teoria e prática nos novos estudos do letramento. In: MAGALHÃES, I. (Org.). Discursos e práticas de letramento: pesquisa etnográfica e formação de professores. Campinas: Mercado de Letras, 2012. p. 6992.

VOLÓCHINOV, V. Marxismo e filosofia da linguagem: problemas fundamentais do método sociológico na ciência da linguagem. 1. ed. São Paulo: Editora 34, 2017.

XAVIER, A. C. A era do hipertexto: linguagem e tecnologia. 2. ed. Recife: Pipa Comunicação, 2013.

YOKOTA, J.; TEALE, W. H. Picture books and the digital world: educators making informed choices. The Reading Teacher, v. 67, n. 8, p. 577-585, 2014. 